\title{
REGISTROS DE PATENTES E SUAS RELAÇÕES COM AS CADEIAS PRODUTIVAS LOCAIS: A EXPERIÊNCIA DA UNIVERSIDADE FEDERAL DO TOCANTINS
}

Patent records and their relationships with local productive chains: the experience of the Federal University of Tocantins

Registros de patentes y sus relaciones con las cadenas productivas locales: la experiencia de la Universidad Federal de Tocantinas

\section{Pedro Eliagi de Oliveira ${ }^{*}$, Ana Lúcia de Medeiros $^{2}$, Kleber Abreu Sousa ${ }^{3}$}

${ }^{1}$ Curso de Ciências Econômicas, Universidade Federal do Tocantins, Palmas, Brasil.

${ }^{2}$ Programa de Pós Graduação em Desenvolvimento Regional - PPGDR (Doutorado), Universidade Federal do Tocantins, Palmas, Brasil.

${ }^{3}$ Programa de Pós Graduação em Propriedade Intelectual e Transferência de Tecnologia para a Inovação - PROFNIT (Mestrado), Universidade Federal do Tocantins, Palmas, Brasil.

*Correspondência: e-mail: pedroeconomista10@gmail.com

\section{Artigo recebido em 28/05/2020 aprovado em 30/10/2020 publicado em 30/12/2020.}

\section{RESUMO}

Este artigo discute como a Universidade Federal do Tocantins (UFT) é capaz de contribuir com o desenvolvimento do estado através da transferência de tecnologia para a inovação, especialmente por meio da concepção e registro de patentes que tenham adesão às cadeias produtivas do estado do Tocantins. A metodologia utilizada na pesquisa foi quantitativa e documental, ao utilizar dados secundários do Núcleo de Inovação Tecnológica (NIT) da UFT e da Federação das Indústrias do Estado do Tocantins (FIETO). Os resultados demonstram um crescimento exponencial dos registros de patentes desde o início das atividades do NIT, em 2012. Ao relacionar as patentes registradas com as cadeias produtivas locais, foram detectadas patentes que possuem aderência a onze cadeias produtivas diferentes, com variadas aplicações no setor agrícola, transporte, construção civil, alimentação, indústria química e tratamento de resíduos urbanos; o que sugere a necessidade de estruturação de uma agenda específica conjunta entre os pesquisadores da UFT e os atores envolvidos nas cadeias produtivas locais do Estado.

Palavras-chave: cadeia produtiva; inovação; patentes

\begin{abstract}
This article discusses how the Federal University of Tocantins (UFT) is able to contribute to the development of the state through the transfer of technology for innovation, especially through the design and registration of patents that adhere to the productive chains of the state of Tocantins. The methodology used in the research was quantitative and documentary, using secondary data from the Technological Innovation Center (NIT) at UFT and the Federation of Industries of the State of Tocantins (FIETO). The results demonstrate an exponential growth of patent registrations since the beginning of the activities of the NIT, in 2012. When relating the registered patents with the local production chains, patents were detected that have adherence to eleven different production chains, with varied applications in the agricultural sector, transport, civil construction, food, chemical industry and urban waste treatment; which suggests the need for structuring a specific joint agenda between UFT researchers and the actors involved in the state's local production chains.
\end{abstract}

Keywords: production chain; innovation; patentes 


\section{RESUMEN}

Este artículo analiza cómo la Universidad Federal de Tocantins (UFT) puede contribuir al desarrollo del estado a través de la transferencia de tecnología para la innovación, especialmente a través del diseño y registro de patentes que se adhieren a las cadenas productivas del estado de Tocantins. La metodología utilizada en la investigación fue cuantitativa y documental, utilizando datos secundarios del Centro de Innovación Tecnológica (NIT) de UFT y la Federación de Industrias del Estado de Tocantins (FIETO). Los resultados demuestran un crecimiento exponencial de los registros de patentes desde el comienzo de las actividades del NIT, en 2012. Al relacionar las patentes registradas con las cadenas de producción locales, se detectaron patentes que se adhieren a once cadenas de producción diferentes, con diversas aplicaciones en el sector agrícola. , transporte, construcción civil, alimentación, industria química y tratamiento de residuos urbanos; lo que sugiere la necesidad de estructurar una agenda conjunta específica entre los investigadores de UFT y los actores involucrados en las cadenas de producción locales del estado.

Descriptores: cadena de producción; innovación patentes

\section{INTRODUÇÃO}

As Instituições de Ensino Superior (IES) públicas brasileiras assumem um papel de relevância como agentes transformadores da realidade social (GARCIA et al, 2018). Acredita-se, que as Universidades devem assumir uma missão precípua, que é a de estimular o desenvolvimento sócio econômico das regiões nas quais estão inseridas por meio, principalmente, da geração de ciência e novas tecnologias. O Tocantins é o mais novo estado da região Norte e está localizado dentro de um complexo econômico com vocações naturais voltadas para o agronegócio. As projeções para este setor sinalizam uma expansão de $21,6 \%$ para a produção de grãos além do aumento de $14,5 \%$ na área plantada, e, o Tocantins está dentro desse contexto. (BUAINAN e GARCIA, 2015).

De posse desses dados, percebe-se a necessidade do estado se preparar para produzir não apenas os grãos (commodities), mas, também, investir em tecnologia e inovação para agregar valor ao produto final, que na grande maioria das vezes é exportado na sua forma mais bruta; e, para isso é necessário agregar o conhecimento científico ao grão para que o estado possa elevar a sua competividade. Nesse sentido, a universidade enquanto instituição que produz conhecimento deve subsidiar uma importante contribuição no desenvolvimento dos setores econômicos ao propor novas soluções que consigam ser materializadas em registros de softwares e patentes em suas mais diversas formas. Essa pesquisa tem como justificativa realizar um levantamento do estado da arte do conhecimento produzido na UFT, especificamente, no que tange ao registro de patentes que podem induzir a diversificação da produção no estado e o aumento da produtividade dos setores econômicos. É importante agregar visibilidade ao trabalho científico da universidade, pois de acordo com Neto e Neme (2012), para o cientista, quanto maior a velocidade e amplitude da circulação de suas ideias, mais vantajoso para o seu prestígio e reconhecimento; já no ambiente de mercado a vantagem reside em tirar proveito da apropriação privada do conhecimento produzido.

Os processos interativos que capacitam o conhecimento a movimentar as engrenagens da economia atendem pelo nome de inovação. E é precisamente a capacidade das economias de incorporar, adaptar e produzir inovações de modo ininterrupto que viabiliza ganhos crescentes de eficiência na atividade econômica. (ARBIX; MIRANDA, 2017). Percebe-se aqui de forma nítida a relação da inovação com o ganho de competitividade. Segundo Yang et al (2010), complexidade e interação 
sistêmica são características importantes dos trabalhadores de conhecimento. Ordenamento próprio mediante desenvolvimento de processos mais complexos, por exemplo, estratégias de evolução, são sinais de reflexão sobre temas como "onde estamos?", "onde queremos chegar?".

As Universidades, em especial aquelas tradicionais, chegaram a uma encruzilhada: ou incorporam a inovação ou serão superadas. Schumpeter (1962), a respeito das dificuldades em inovar, afirma que: "Não apenas é objetivamente mais difícil fazer algo novo do que fazer o que é conhecido e testado pela experiência, mas o indivíduo se sente relutante em fazê-lo e assim seria mesmo que as dificuldades objetivas não existissem. É assim em todos os campos. A história da ciência é uma grande confirmação do fato de que consideramos excessivamente difícil adotar um ponto de vista científico ou um método novo. O pensamento volta repetidamente à trilha habitual, mesmo que tenha se tornado inadequada e mesmo que a inovação mais adequada em si mesma não apresente nenhuma dificuldade particular". (SCHUMPETER, 1962, p. 9293).

Audy (2017), afirma que a mudança pela qual passa a educação atualmente só se iguala a dois outros momentos na história da humanidade, em comum, esses são períodos de inovações disruptivas: quando houve o surgimento das escolas na antiguidade clássica grega, que revolucionou devido ter criado a educação formal; e o advento do livro impresso, na Europa do séc. XV, permitindo maior difusão de informações e melhora dos registros de todo o conhecimento produzido pela humanidade. Somado a isso, está o momento histórico atual, das tecnologias online de aprendizagem. Portanto, se tratando de mudanças disruptivas, estamos num momento crítico, e, por isso, a comunidade acadêmica necessita de respostas face as novas demandas que pressionam as universidades.

Etkowitz (2001) analisa que, historicamente, o ensino, que é a primeira missão da universidade, e remonta aos séculos XI e XII, quando surgem as primeiras universidades na Europa, marcou naquele momento o próprio surgimento da ideia de 'ensino superior'. A pesquisa, no século XIX, firma-se como a primeira revolução na missão universitária, pois torna-se também uma missão institucional. A vanguarda da primeira revolução acontece especialmente na Alemanha, na França e na Inglaterra. Na segunda metade do século XX, em especial nos Estados Unidos, surge a segunda revolução na missão universitária, com a emergência da inovação e a atuação da universidade como vetor (e protagonista) do processo de desenvolvimento econômico e social da sociedade onde está inserida.

No Brasil, o tripé ensino, pesquisa e extensão é a denominação local da tendência mundial estabelecida a respeito das três funções da universidade. Para que as instituições de ensino superior sejam vetores do desenvolvimento econômico e social deve haver uma estrutura sólida nos três pilares universitários. Clark (2003), discorrendo sobre o assunto, afirma que a melhor forma de conhecer as universidades é "mergulhando nas configurações internas que promovem diretamente pesquisa, ensino e aprendizagem" (CLARK, 2003, p.2). O autor afirma ainda que, com base em estudos de caso realizados entre 1994-96, generalizou cinco elementos presentes nas universidades mais reconhecidas como indutoras do desenvolvimento econômico: base de financiamento diversificada; núcleo de direção atuante; grande alcance; estímulo a 
cultura universitária e, por fim, uma cultura empreendedora integrada.

Pinho (2008) destaca que o reconhecimento da importância das relações entre universidades e empresas se disseminou também no Brasil, mas o relacionamento ainda não é bem conhecido nem muito menos sistematicamente caracterizado. $\mathrm{O}$ crescimento e o fortalecimento das várias formas de interações entre universidades e empresas definem um importante componente para o Brasil e mostra a necessidade de se construir um sistema completo de inovação.

Edquist (2011) afirma que a importância dada ao processo de pesquisa e desenvolvimento realizado por empresas ou outras instituições, como universidades e institutos, é distinta para cada país, embora o relacionamento entre todas as instituições seja crucial. Países que negligenciam P \& D estão sujeitos a questão da evasão de cérebros. Segundo Brooks e Waters (2011, p. 143), tratam se das "perdas sofridas por nações que mandam um número considerável de estudantes para o exterior". Taylor (2010) comenta:

\footnotetext{
"Os governos que procuram desenvolver suas próprias instituições nacionais de ensino superior, a fim de atender às necessidades nacionais de habilidades e conhecimentos, e para trazer impacto nacional sobre a economia do conhecimento, deve se preocupar com a evasão de cérebros. Os estudantes vão estudar no exterior, muitos dos quais não podem retornar". (TAYLOR, 2010, p.90).
}

As universidades compõem uma parte do conjunto institucional contemporâneo, sejam elas de natureza pública ou privada. Os demais agentes públicos e privados completam todo esse grande conjunto de instituições que dão base a sociedade. Em comum, todos necessitam seguir princípios. North
(1991. p.3) define as instituições como "as regras do jogo em uma sociedade ou, de modo mais formal, [...] as restrições arquitetadas pelos homens que dão forma a sua interação". Com isso, North faz uma distinção entre instituições e organizações, entendendo as primeiras como as regras do jogo e as segundas como os seus jogadores. (RODRIGUES, 2013) Como política de desenvolvimento regional, a própria criação das universidades atrai investimentos, pessoas, capital, que alocados nas cidades permitem requalificar e dinamizar as economias locais, podendo até levar a especializações dos lugares (OLIVEIRA JR, 2014, p. 7).

Hirschman (1985), discutido por Dallabrida (2017), na Teoria dos Encadeamentos, parte do pressuposto de que o progresso econômico não ocorre ao mesmo tempo em todos os locais e, quando ocorrido, gera forças poderosas que buscam manter concentrado espacialmente o crescimento econômico, em torno dos pontos onde se inicia. $\mathrm{O}$ autor sustentase na observação de que uma das principais dificuldades das estratégias de crescimento equilibrado consiste no fato de não haver disponíveis em volume suficiente, capitais, pacotes de inovações e empresários aptos e dispostos a assumir riscos. Considerando esses três fatores escassos elencados por Hirschman, um deles pode ser diretamente suprido pelas universidades: a geração de inovação. O ensino superior agrega também mão de obra qualificada, potencializando o capital humano de uma região, além de promover inovações que reforcem a competitividade das cadeias de valor regionais e gerem o desejado desenvolvimento autônomo.

Segundo Torkomian (1997) as universidades apresentaram substancial amadurecimento no desempenho de suas atividades direcionadas ao desenvolvimento econômico. Foram criadas estruturas 
internas universitárias com objetivo de facilitar o transbordamento do conhecimento científico para o meio empresarial, mediante o desenvolvimento de pesquisas conjuntas entre universidades e empresas, a geração de spinoffs acadêmicos e o licenciamento de patentes depositadas pelas universidades.

Esse amadurecimento não aconteceu de forma homogênea. Mowery e Sampat (2005) afirmam que os países em desenvolvimento promoveram mais recentemente a aproximação entre universidades e o setor produtivo, isso pode ser observado pela criação de parques científicos e tecnológicos, pelas pesquisas conjuntas, além da atuação das incubadoras e empresas startups.

Na região Amazônica, Almeida et al (2008) descreve que o início do processo de criação de universidades federais ocorreu na década de 1950, com a Universidade Federal do Pará (UFPA), criada em 1957. Já no Tocantins a criação da primeira universidade federal ocorreu somente em 2000 e teve a implantação concluída em 2003, com a fundação da Universidade Federal do Tocantins. Uma diferença acima de 40 anos entre a criação da primeira universidade federal do Norte, e a implantação da UFT. Se essa diferença temporal for comparada ao surgimento da primeira Universidade Brasileira, no Rio de Janeiro, ocorrida na década de 1930, o hiato temporal chega a quase 70 anos. Ou seja, o próprio processo de criação de universidades no Brasil não foi homogêneo. Ou seja, políticas regionalizadas de desenvolvimento estão sendo praticadas no Brasil a pelo menos uma década, devido o reconhecimento da efetividade dessa estratégia. $\mathrm{O}$ desenvolvimento das cadeias produtivas regionais faz parte do conjunto de políticas de desenvolvimento regionalizadas.

Dentro da afirmativa de que as Universidades possuem importância crítica para a promoção do desenvolvimento regional, a questão central deste trabalho é responder a seguinte pergunta: Quais são os registros de patentes desenvolvidos pela UFT, e qual a adesão dessas patentes às cadeias produtivas locais do Estado.

\section{METODOLOGIA}

As técnicas de pesquisa utilizadas neste trabalho, se caracterizam como descritiva e documental, sendo ancoradas em uma abordagem eminentemente quantitativa. Esta pesquisa é, também, de característica marcadamente aplicada, isto é, caracteriza-se por seu interesse prático e seus resultados serem utilizados na solução de problemas que ocorrem na realidade (VERGARA, 2003). Para a construção dessa pesquisa houve uma participação ativa do Núcleo de Inovação Tecnológica (NIT) da UFT. Sobre a orientação normativa essa pesquisa se baseou no Manual de normalização para elaboração de trabalhos acadêmicos-científicos da Universidade Federal do Tocantins / UFT, elaborado pela equipe do Sistema de Bibliotecas da Universidade, em 2017.

A pesquisa se desenvolveu em quatro etapas. Primeiro, a revisão de literatura, a qual respondeu às seguintes questões: quem já escreveu e o que já foi publicado sobre o assunto, que aspectos já foram abordados, quais as lacunas existentes na literatura. Pode objetivar determinar o "estado da arte", ser uma revisão teórica, entre outros. (PRODANOV; FREITAS, 2013, p. 78). Para escolha e delimitação do tema foi observada a pertinência do assunto na atualidade, oportunidade e dados disponíveis. Há bibliografia acessível e atual, além de demanda institucional e social por essa discussão.

A coleta de dados foi a segunda etapa. Foram coletados dados em fontes secundárias, a partir dos periódicos disponíveis no portal da CAPES, Google 
Acadêmico, Scielo e Portal da UFT. Os dados estatísticos foram obtidos a partir do Instituto Brasileiro de Geografia e Estatística - IBGE, Secretaria da Fazenda do Tocantins / SEFAZ-TO, Núcleo de Inovação Tecnológica / NIT-UFT e Instituto Nacional da Propriedade Industrial - INPI. Foi feita também uma pesquisa descritiva, com análise documental de regimentos, normativas e deliberações que demonstram a postura institucional com relação ao tema, especialmente no caso da Universidade Federal do Tocantins, que é o objeto delimitado de estudo dessa monografia.

A terceira etapa consistiu na organização e tabulação dos dados. As informações coletadas foram tabuladas em subgrupos, em geral separados por subtópicos, e reunidos de modo que as hipóteses pudessem ser comprovados ou refutadas. (LAKATOS E MARCONI, 2003, p.167). Foi realizada uma leitura prévia dos resumos de alguns artigos que tratam sobre inovação nas universidades e interação com empresas. Em seguida, foi organizada a documentação, que consistiu no manejo de informações, por meio de fichamentos: resumo, transcrições, apreciações etc. Posteriormente, foi feita a análise e seleção do material levantado, procurando confrontar os dados colhidos, analisar os pontos de vista divergentes e convergentes, para escolher o que mais se adapta aos objetivos da pesquisa planejada.

$\mathrm{Na}$ quarta etapa foi realizada a apresentação e a discussão dos dados. Todos os dados levantados são de natureza pública, mas buscou-se informações específicas neles: caminhou-se do geral para o específico, em busca de formular uma hipótese.

\section{RESULTADOS E DISCUSSÕES}

O Instituto Nacional da Propriedade Industrial INPI (2017), órgão responsável pelo registro e regulação de patentes no Brasil, destaca que a Classificação Internacional de Patentes - IPC divide as áreas tecnológicas nas classes A à $\mathrm{H}$. Ou seja, as invenções realizadas em qualquer local do planeta podem ser classificadas em até oito classes. Dentro de cada classe, há subclasses, grupos principais e grupos, através de um sistema hierárquico. São cerca de 70 mil grupos no IPC.

Desde 2014 o INPI também adota a Classificação Cooperativa de Patentes (CPC) para classificar os pedidos, esse segundo sistema foi criado pelo EPO/USPTO, baseado na IPC, sendo apenas mais detalhado, pois possui em torno de 200 mil grupos. Uma vez identificado o(s) grupo(s) ao(s) qual(s) o pedido de patente se refere, é fácil identificar outros pedidos de patentes relacionados ao mesmo fim. $\mathrm{O}$ quadro 1 demonstra, através de uma das patentes registradas via UFT, como funcionam os níveis do IPC:

Quadro 1. Exemplo dos níveis do IPC.

\begin{tabular}{|c|c|l|}
\hline \multicolumn{3}{|c|}{ Código IPC "A01N 37/02" } \\
\hline Seção & A & Necessidades Humanas \\
\hline Classe & 1 & $\begin{array}{l}\text { Agricultura; silvicultura; pecuária; caça; } \\
\text { captura em armadilhas; pesca }\end{array}$ \\
\hline Subclasse & N & $\begin{array}{l}\text { Conservação de corpos de animais ou } \\
\text { plantas; biocidas, como desinfetantes, } \\
\text { pesticidas e herbicidas; repelentes ou } \\
\text { atrativos de pestes; reguladores do } \\
\text { crescimento de plantas }\end{array}$ \\
\hline Subgrupo & $37 / 02$ & $\begin{array}{l}\text { Ácidos carboxílicos saturados ou tio } \\
\text { análogos dos mesmos; derivados dos } \\
\text { mesmos. }\end{array}$ \\
\hline
\end{tabular}

Fonte: elaboração própria a partir da IPC - INPI (2017).

Um importante marco temporal ocorrido no Brasil no âmbito do avanço dos registros de patentes foi a Lei de Inovação $n^{\circ} 10.973$, promulgada em dezembro de 2004 e regulamentada em outubro de 2005. Sua promulgação foi responsável por definir as regras quanto à participação dos criadores da 
tecnologia nos ganhos econômicos gerados pela proteção de propriedade intelectual, por estimular as parcerias entre universidades e empresas e pela instalação e/ou aperfeiçoamento dos núcleos de inovação tecnológica nas universidades (CASTRO, SOUZA, 2012).

Enquanto algumas universidades criaram seus núcleos de inovação tecnológica apenas depois da promulgação da Lei de Inovação, outras já contavam com escritórios de transferência de tecnologia incumbidos de auxiliar seus pesquisadores a gerenciar os seus pedidos de patentes até dez anos antes dessa lei entrar em vigor. Tal situação justificaria a atual diferença de amadurecimento, estrutura e capacitação entre os núcleos (TORKOMIAN, 2009). No entanto, com a obrigatoriedade instaurada pela Lei 10.973, da instalação dos NITs em todos os ICT, não apenas foram formalizadas suas atividades e funções, como a gestão da inovação tecnológica dentro das universidades foi definida como uma ação política estratégica para o país.

Na UFT, o Núcleo de Inovação Tecnológica NIT foi criado em 2011 por meio da Resolução do Conselho de Ensino, Pesquisa e Extensão (CONSEPE) $n^{\circ} 02 / 2011$, estando em conformidade com a Lei de Inovação (Lei n ${ }^{\circ} 10.973$ de 02/12/2004 e regulamentada pelo Decreto $n^{\circ} 5.563$ de 11/10/2005), vinculado à Pró-reitora de Pesquisa e Pós-Graduação no prédio da Reitoria.

A UFT (2019) em matéria jornalística veiculada em maio de 2019 no seu site oficial, ressaltou, com dados do NIT da instituição, que a Universidade tem uma patente internacional, depositada via Tratado de Cooperação de Patentes (PCT), além de 29 pedidos de patentes em nível nacional depositados no Instituto Nacional de Propriedade Industrial (INPI) e dez pedidos em análise pelo NIT. Também foram concedidos 16 registros de programas de computador (software) criados na UFT, além de outros três registros de software em tramitação.

O gráfico 1 destaca, por ano, os pedidos de registro de patentes e programas de computador no NIT - UFT, desde seu início em 2012:

De acordo com o gráfico 1 é possível perceber que o registro de patentes com titularidade da UFT está crescendo exponencialmente. Somente no período entre maio de 2018 e outubro de 2019, o número de solicitações de registro para patenteamento cresceu $30 \%$ em relação a todas as patentes depositadas anteriormente. Sobre a eficácia dos pedidos de patente registrados na UFT, das 30 patentes que ultrapassaram o período de sigilo e tramitação no INPI até outubro de 2019, 21 foram deferidas, portanto, tem-se um índice de deferimento na ordem de $70 \%$ dos registros de patentes protocolados.

Gráfico 1. Depósito de patentes na UFT de 2012 a 2018.

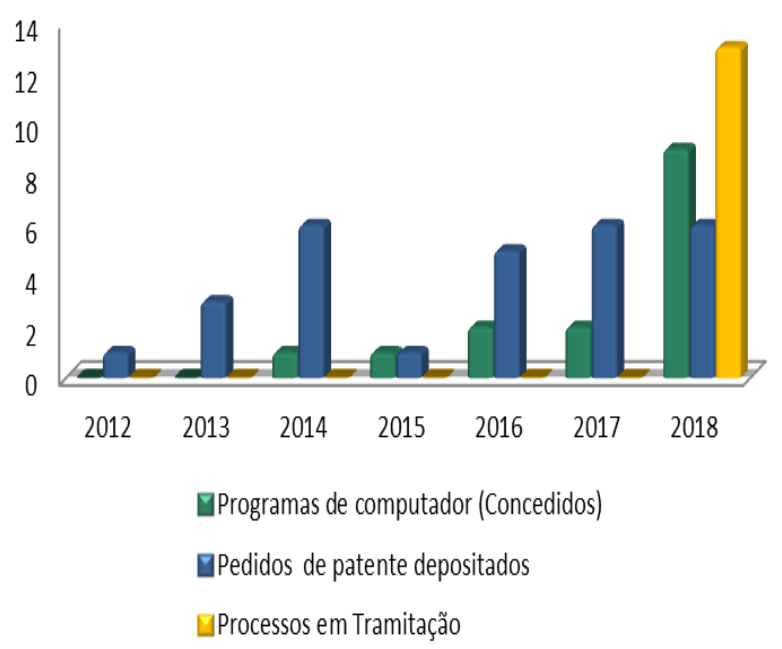

Fonte: NIT - UFT (2019).

A perspectiva para o depósito de patentes por meio de universidades brasileiras apresentou avanços significativos após a Lei de Inovação, e a participação dessas instituições de ensino superior no sistema nacional de inovação vem aumentando 
gradativamente. Souza e Castro (2012), em entrevista com representantes dos NITs INOVA/UNICAMP e SEDETEC/ UFRGS, recebem o relato que, nesses NITs, procura-se respeitar as vontades e interesses dos grupos de pesquisa quando esses negociam projetos e licenciamentos, e as agências costumam se ocupar com todos os acordos, leis, trâmites relacionados à propriedade intelectual e sua comercialização, deixando ao pesquisador "apenas a função de pesquisar", embora a equipe se preocupe a informar e aproximar o pesquisador de toda a negociação de contratos. As Agências de Inovação da USP e da UFRJ também buscam adotar essa postura. Entretanto, parece haver uma maior preocupação com a necessidade de transformar aquela criação em inovação, ou seja, em produtos comercializáveis, que gerem recursos financeiros para a Universidade e para o país. Na UFT, a criação de patentes tem se voltado a gerar novas ideias e produtos comercializáveis para as cadeias produtivas.

Ao se tratar de cadeias produtivas, essas, segundo FIETO (2018) possuem diferentes elos, por exemplo, a cadeia do arroz, possui os fornecedores de insumos e serviços, os agricultores e sua respectiva produção, as unidades de armazenagem e secagem, a indústria processadora e transformadora, o mercado de atacado e varejo e, por fim, o consumidor final interno ou externo. Então, na busca pela classificação de uma patente de upatnte determinada cadeia produtiva, a finalidade dessa invenção pode ser válida nos mais variados elos dessa cadeia. FIETO (2018) apresenta cinco cadeias produtivas prioritárias, segundo o governo estadual, para o desenvolvimento do Tocantins: soja, milho, pecuária, arroz, silvicultura (madeira reflorestada), psicultura. A UFT possui, pelo menos, uma patente registrada em cada uma dessas cadeias produtivas agrícolas, com exceção da silvicultura. Foram identificadas patentes destinadas também às demais áreas de aplicação: tratamento de efluentes, saúde ou laboratorial, frutos do bioma, construção civil, indústria de alimentação e destinação de resíduos. Com base nisso, o gráfico 2 apresenta a distribuição das patentes registradas na UFT por cadeia produtiva ou área de aplicação:

O Gráfico 2 mostra a distribuição das patentes desenvolvidas pela UFT por cadeia produtiva do estado e nessa mesma direção foi feito um estudo por Calzolaio et al (2017) que mostrou as especialidades tecnológicas da Universidade Federal do Rio Grande do Sul - UFRGS, através dos pedidos de patentes apresentados pela instituição. Os pesquisadores da UFRGS utilizaram o software Orbit, um banco de dados comercial, para gerar a classificação das patentes, pois era um conjunto significativo de dados que envolvia 344 depósitos patentários. Na UFT, a busca e sistematização dos dados aconteceu de forma manual, pois apenas 21 depósitos de patentes da Universidade já estavam deferidos e disponíveis para consulta no INPI até outubro de 2019.

Gráfico 2. Distribuição das patentes registradas na UFT por área de aplicação.

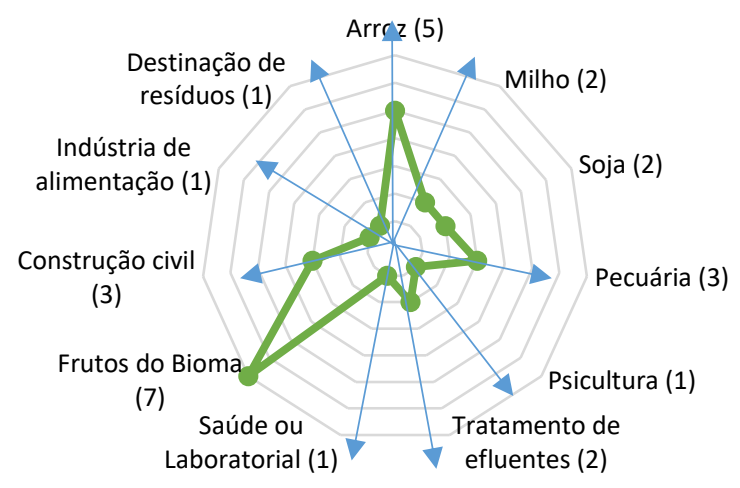

Fonte: Elaboração própria a partir de dados do INPI (2019) e NIT-UFT (2019a). 
No gráfico 3 são apresentados os dados da "Seção" e "Subclasse" a que pertencem os registros de patentes da UFT, ou seja, esse gráfico classifica as patentes produzidas de acordo com o padrão internacional. A análise conduzida considera apenas o primeiro código IPC por patente, o que é o procedimento padrão para esse tipo de análise. Optouse por esses dois níveis de detalhamento para que seja possível, assim como na UFRGS, apresentar qual a especialidade tecnológica da UFT, em termos de patentes. O gráfico 3 apresenta os níveis hierárquicos onde a UFT possui patentes aprovadas:

Gráfico 3. Patentes publicadas na UFT.

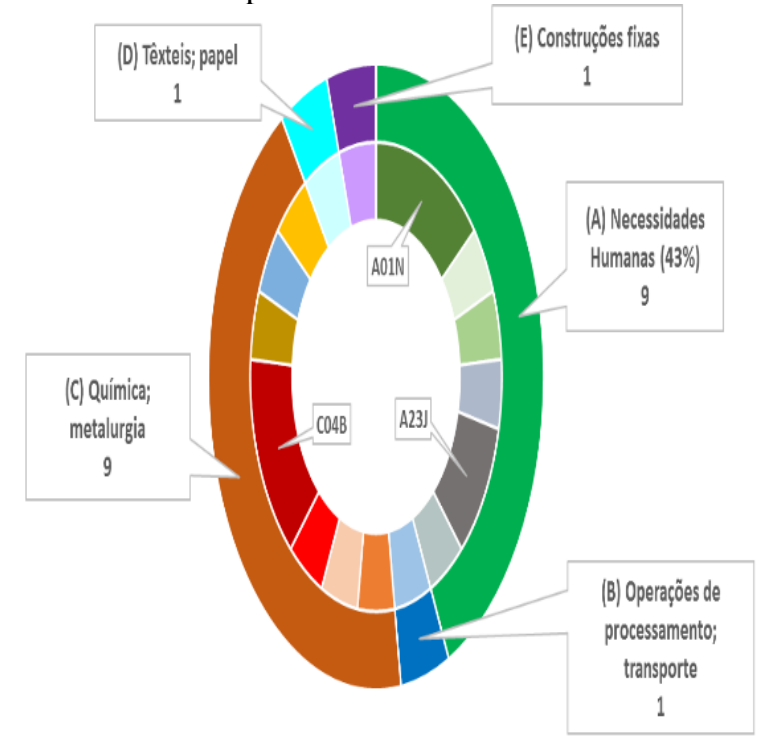

Fonte: elaboração própria a partir de dados do INPI (2019) e NIT-UFT (2019a).

A UFT possui patentes aprovadas em 5 sessões (anel exterior), 12 classes, 16 subclasses (anel interior) e 20 subgrupos. $86 \%$ das patentes depositadas até outubro de 2019 na UFT se enquadram em duas sessões: "Necessidades Humanas" (inclui agricultura e produção de outros insumos básicos para o ser humano) e "Química e Metalurgia". Portanto, das oito classes de inovação existentes, os pesquisadores da UFT mais depositaram patentes em duas dessas. No gráfico a legenda do anel exterior mostra o nome da sessão e o número de patentes registradas em cada. A legenda do anel interior destaca as 3 subclasses que possuem mais de uma patente registrada na UFT: São 3 registros na A01N (conservação de corpos de plantas ou animais; biocidas, 2 registros na A23J (composições ou preparações à base de proteínas ou para produtos alimentícios). As demais subclasses possuem uma patente registra em cada, e são organizadas pelos seguintes códigos: A23B, A23C, A23D, A23L, B65F, C01F, C02F, C03C, C07H, C08B, C12M, D03D, E0 como pesticidas e herbicidas; repelentes ou atrativos de pestes) e C04B (cimentos, argamassas, concreto, pedra artificial, cerâmica e suas composições.

$\mathrm{Na}$ coleta de dados para a elaboração desse capítulo foram também sistematizados os Softwares registrados no INPI com titularidade da UFT. Mas, constatou-se que os programas de computador desenvolvidos pela Universidade possuem abordagem mais relacionada a gestão estratégica direcionada a educação, normas e diretrizes e outras tomadas de decisões envolvendo gestores públicos. Há dois softwares com finalidade de atender a agricultura e arborização urbana, e outros dois de gestão de recursos hídricos do estado, os quais se chamam: Sistema de Informação Gestão de Alto Nível (GAN/IAC/UFT), depositado no INPI em 30/05/2018, que monitora e faz a gestão dos recursos hídricos através das estações de monitoramento da Agência Nacional das Águas; Sistema de Informação Gerencial para Irrigação SIGI, depositado no INPI em 08/11/2016 que viabiliza o controle da agricultura irrigada no Estado do Tocantins, auxiliando no gerenciamento de informações disponíveis a todos os atores envolvidos na agricultura irrigada do Estado.

Se a estrutura física de uma instituição deve ser uma expressão de sua estrutura funcional, no caso de 
uma universidade, sua estrutura acadêmica precisa ser planejada de forma estratégica, a fim de suprir as necessidades básicas de suas atividades fins que se desenvolvem em princípio nos espaços ditos acadêmicos: departamentos, salas de aula, laboratórios, salas de professores, salas especiais e outros específicos como biblioteca, editora, institutos de pesquisa, dentre outros. (SILVA, 2003)

A UFT possui toda uma estrutura acadêmica, administrativa, operacional que possibilita a realização das atividades de ensino, pesquisa e extensão. Nessa estrutura, também estão inseridos os locais que mais geram inovação: os laboratórios de pesquisa, institutos, núcleos, incubadoras e empresas juniores. Trata-se de um ecossistema com diversas conexões e capacidade de trabalho nas mais diversas áreas do conhecimento. Os dados apresentados nos quadros 4, 5 e 6 foram sistematizados de acordo com a 'Tabela das Áreas do Conhecimento', da CAPES (2014), a qual subdivide o conhecimento científico em 8 grandes áreas. $\mathrm{O}$ quadro 2 demonstra a distribuição dos laboratórios da UFT nos câmpus da Universidade:

Quadro 2. Laboratórios da UFT.

\begin{tabular}{|c|c|c|c|c|c|c|c|c|}
\hline \multirow[b]{2}{*}{ Área do Conhecimento } & \multicolumn{7}{|c|}{ Câmpus } & \multirow{2}{*}{$\begin{array}{r}\text { Total po } \\
\text { Área }\end{array}$} \\
\hline & Araguaina & Arraias & Gurupi & Miracema & Palmas & \begin{tabular}{c|} 
Potto \\
Nacional
\end{tabular} & Tocantinópolis & \\
\hline Ciências Exatas e da Terra & 5 & & 3 & & 5 & & & 13 \\
\hline Ciências Biológicas & 8 & & 4 & 1 & 5 & 3 & & 21 \\
\hline Engenharias & & & 1 & & 12 & & & 13 \\
\hline Ciências da Saúde & 1 & & 1 & 1 & 4 & & & 7 \\
\hline Cièncias Agrárías & 3 & & 2 & & 3 & & & 8 \\
\hline Ciências Sociais Aplicadas & & & & & 3 & 1 & & 4 \\
\hline Ciências Humanas & 9 & & & & 1 & 3 & 1 & 14 \\
\hline Linguistica, Letras e Artes & 1 & 1 & & & 2 & & 1 & 5 \\
\hline Total por Câmpus & 27 & 1 & 11 & 2 & 35 & 7 & 2 & \\
\hline
\end{tabular}

Fonte: elaboração própria a partir dos dados do NIT - UFT (2019a).
A disponibilidade de laboratórios na UFT acompanha as áreas do conhecimento dos cursos ofertados em cada campus. São espaços especialmente de aprendizagem, mas também com um grande potencial de funcionamento voltado à inovação, caso estejam ligados a estruturas como, por exemplo, as Incubadoras. As quais, de acordo com as informações de UFT $(2013,2016)$ e CONSEPE-UFT (2019) são três: "Incubadora de Empresas de Biotecnologia da UFT (HABITE)", que funciona no campus de Gurupi desde 2013; a Incubadora de Empresas do campus de Palmas, criada em 2014; e a mais recente, aprovada pela resolução CONSEPE $\mathrm{N}^{\circ} 28$ - de agosto de 2019, a "Incubadora OPAJE de Projetos e Inovação, de Base Tecnológica e Pedagógico-Social”.Os Institutos de Pesquisa e Extensão da UFT também fazem parte da estrutura universitária. São 6 institutos, com a missão em comum de aproximar a sociedade do capital intelectual disponível na universidade. Em geral exercem grande interdisciplinaridade em sua atuação, englobando inclusive mais de uma área do conhecimento em sua missão atuante. Os institutos também são caracterizados por possuírem participantes e projetos em diversos campus ou regiões do Tocantins, por isso não é possível classificar os mesmos de acordo com a variável campus. Isso está demonstrado no quadro 3.

Sobre os núcleos de extensão, que são outra possível fonte de inovação na universidade, esses possuem como missão apoiar, planejar, organizar, elaborar e executar programas relativos à pesquisa $\mathrm{e}$ extensão visando complementar as atividades dos cursos de graduação e pós-graduação. (PROEX-UFT, 2012). O quadro 4 apresenta os núcleos da UFT por área do conhecimento e qual campus se localizam. Devido os dados serem do ano de 2012, pode haver 
núcleos já existentes que ainda não constam no levantamento.

\begin{tabular}{|c|c|}
\hline \multicolumn{2}{|r|}{ Quadro 3. Institutos da UFT. } \\
\hline Área do Conhecimento & Nome \\
\hline Ciências Biológicas & Instituto de Pesquisa e Extensão em Biodiversidade (Ipex-Bio) \\
\hline Engenharias & Instituto de Atenção às Cidades (IAC-UFT) \\
\hline \multirow{3}{*}{ Ciências Sociais Aplicadas } & $\begin{array}{l}\text { Instituto de Pesquisa e Extensão de Desenvolvimento } \\
\text { Regional do Centro Norte Brasileiro (Ipex-Regional) }\end{array}$ \\
\hline & $\begin{array}{l}\text { Instituto de Pesquisa e Extensão do Empreendedorismo } \\
\text { Inovador do Tocantins (Ipex-Eito) }\end{array}$ \\
\hline & Instituto de Pesquisa e Extensão Comunicação, linguagens e \\
\hline Ciências Humanas & Sociedade (Ipex-Colis) \\
\hline Linguistica, Letras e Artes & Instituto de Pesquisa e Extensão em Educação (Ipex-Edu) \\
\hline
\end{tabular}

Fonte: elaboração própria a partir de UFT (2016b).

Quadro 4. Núcleos da UFT.

\begin{tabular}{|c|c|c|c|c|c|c|c|c|}
\hline \multirow[b]{2}{*}{ Área do Conhecimento } & \multicolumn{7}{|c|}{ Campus } & \multirow{2}{*}{$\begin{array}{l}\text { Total } \\
\text { por } \\
\text { Área }\end{array}$} \\
\hline & Araguáína & Arraias & Gurupi & Miracema & Palmas & $\begin{array}{c}\text { Porto } \\
\text { Nacional }\end{array}$ & Tocantinópolis & \\
\hline Ciências Exatas e da Terra & & & & & 1 & & & 1 \\
\hline Ciências Biológicas & & & & & & 1 & & 1 \\
\hline Engenharias & & & & & 1 & & & 1 \\
\hline Ciências da Saúde & & & & 1 & 1 & & & 2 \\
\hline Ciências Agrárias & & & & & & & & 0 \\
\hline Ciências Sociais Aplicadas & 1 & 1 & & & 2 & & & 4 \\
\hline Ciências Humanas & 2 & & & & 2 & 5 & & 9 \\
\hline Linguistica, Letras e Artes & 1 & 1 & & & & 1 & & 3 \\
\hline Total porCampus & 4 & 2 & 0 & 1 & 7 & 7 & 0 & \\
\hline
\end{tabular}

Fonte: elaboração própria a partir de Proex-UFT (2012).

\section{CONSIDERAÇÕES FINAIS}

O objetivo central deste trabalho foi estudar os registros de patentes da Universidade Federal do Tocantins (UFT) e a sua relação com as cadeias produtivas locais.

Os dados mostraram que os registros de patentes da UFT estão, de fato, de fato associados às cadeias produtivas do estado. Pode-se constatar esse fato quando se observa que para a cadeia produtiva da soja foram desenvolvidas duas patentes, para a de milho, duas, para a de pecuária, três, para a de arroz, cinco e para a de piscicultura, uma. A UFT produziu patentes que atendem a essas cadeias produtivas prioritárias, com exceção da silvicultura. Há inovação sendo gerada também em outras áreas, como o uso de produtos de frutos do bioma com sete patentes desenvolvidas, difundidas nos seguintes produtos: bacaba (1), babaçu (3), açaí (1), noni (1) e pequi (1), todos utilizados como matérias-primas para seu produto final. Houve também o registro de patentes voltadas a destinação de resíduos sólidos (1), tratamento de efluentes (2), além de produtos com aplicação na indústria da construção civil (3), alimentação (1), e uma patente na área da saúde (1).

Analisar e sistematizar o ambiente de inovação e de empreendedorismo da UFT foi importante para apresentar de maneira concreta que recursos estão disponíveis para contribuir com o desenvolvimento econômico do estado.

A partir dessas constatações identificou-se que os atores envolvidos no processo de inovação na UFT, embora ainda não se possa afirmar que formem um conjunto articulado e eficaz no processo inovativo, apresentam progressos, e cujos dados obtidos podem servir de base para orientar políticas de incentivo ao desenvolvimento local. Constatou-se que a instituição possui 85 laboratórios distribuídos em todas as 8 grandes áreas do conhecimento, e presentes em todos os 7 campus da UFT. O arranjo institucional interno da Universidade que se volta para a oferta de serviços à sociedade está organizado em seis institutos e vinte e um núcleos de pesquisa, além dos 85 laboratórios que estão aptos a desenvolverem e executarem projetos de pesquisa e extensão para a sociedade. Contudo, é razoável observar que apesar do crescente número de patentes desenvolvidas pela UFT, ainda se faz necessária uma maior articulação da Universidade com o setor privado; o que sugere a necessidade de estruturação de uma agenda específica conjunta entre os pesquisadores da UFT e os atores envolvidos nas 
cadeias produtivas locais do Tocantins. A partir daí, é necessário elencar pontos de convergência no que se refere ao desenvolvimento de tecnologias. Outro fator que precisa ser melhor examinado é a formatação legal que esse tipo de acordo de cooperação exige, que se deve convergir com a disposição das empresas.

Também ficou evidenciada a necessidade de pressionar as instituições de apoio à pesquisa do estado, como FAPT, no sentido de desenvolver programas de governo que incentivem a inserção de pesquisadores nas empresas, o que pode ser uma alternativa para uma maior articulação entre a Universidade e a iniciativa privada.

\section{REFERÊNCIAS}

ALMEIDA, L. M. Inovações tecnológicas e interações industriais: um estudo do desenvolvimento local a partir da cadeia intermediária da nokia no PIM. 2008. Dissertação (Mestrado em Economia) - Universidade Federal do Pará, Belém, 2008.

ANDRADE, M. M. Como preparar trabalho para cursos de pós-graduação: noções práticas. 7 ed. São Paulo: Atlas: 2008.

ARBIX, Glauco; MIRANDA, Zil. Políticas de inovação em nova chave. Estudos av. vol. 31 no.90 São Paulo, 2017.

AUDY, Jorge. A inovação, o desenvolvimento e o papel da Universidade. Estudos av. 31 no. 90 São Paulo, 2017.

BRASIL. Presidência da República. Plano Amazônia Sustentável: diretrizes para o desenvolvimento sustentável da Amazônia Brasileira/ Presidência da República. - Brasília: MMA, 2008.

Brooks R, Waters J (2011). Student Mobilities, Migration and the Internationalization of Higher Education. 208 pages. Palgrave MacMillan, Basingstoke 15 Apr 2011. ISBN: 9780230578449.

BUAINAIN, A. M. 1; GARCIA, J. R. Evolução recente do agronegócio no Cerrado Nordestino. Estudos Sociedade e Agricultura, v. 23, p. 166 - 195, 2015.
CALZOLAIO, Aziz. SPRICIGO, Gisele; MONTEIRO, Sérgio M. M. Correspondência entre as Patentes da UFRGS e a Classificação Nacional das Atividades Econômicas. II Encontro Nacional de Economia Industrial e Inovação. Vol. 4 num. 2. Setembro, 2017. Disponível em: https://www.proceedings.blucher.com.br/articledetails/correspondncia-entre-as-patentes-da-ufrgs-eaclassificao-nacional-das-atividades-econmicas-26620 Acesso em 08 nov.2019

CASTRO, Biancca S; SOUZA, Gustavo C. O papel dos Núcleos de Inovação Tecnológica (NITs) nas universidades brasileiras. Liinc em Revista, v.8, n.1, Rio de Janeiro, p.125-140. Março, 2012.

CAPES. Tabela de Áreas de Conhecimento/Avaliação. Brasília, 2014.

CLARK, B. R. Creating entrepreneural universities: organizational pathways of transformation. Oxford: Pergamon-Elsevier Science, 1998.

CONSEPE . Resolução n ${ }^{\circ} 28$, de 21 de agosto de 2019. UFT, câmpus de Palmas. 2019. Disponível em https://docs.uft.edu.br/share/s/xKSK3vdURceoomB0sEG2Q Acesso em 19 nov.2019

DALLABRIDA, Valdir R. Teorias do Desenvolvimento: aproximações teóricas que tentam explicar as possibilidades e desafios quanto ao desenvolvimento de lugares, regiões, territórios ou países. Curitiba: CRV, 2017. 238p.

EDQUIST, Charles. The systems of innovation approach and innovation policy: an account of the state of art. In: DRUID SOCIETY CONFERENCE, 2011, Begin. Druid... Copenhagen: National System of Innovation: Institutions and Public Policies, 2011. Disponível em: https://www.researchgate.net/profile/Charles_Edquist /2 Acesso em: 27 maio. 2019

ETZKOWITZ, H. The second academic revolution and the rise os entrepreneurial Science. IEEE Technology and Society Magazine, v.20, n.2, p.18-29, 2001.

FIETO. Plano Estratégico Para as Cadeias Produtivas do Estado do Tocantins - 2018-2027. Volume 4 arroz. $1^{a}$ edição. Palmas, 2018.

GARCIA, Renato, et al. Estudos de caso da interação universidade-empresa no Brasil. Cedeplar. FACE. 
UFMG.

2018.

Disponível

em:

https://cedeplar.ufmg.br/publicacoes/colecao-

populacao-economia/1069-experiencias-de-interacaouniversidade-empresa-no-brasil Acesso em: 26 maio. 2019

HIRSCHMAN, A. O. (1961) Estratégia do Desenvolvimento Econômico. Rio de Janeiro: Editora Fundo de Cultura S. A. Edição ano 1985.

INPI. Classificação de patentes. Governo Federal do Brasil, 2017. Disponível em: http://www.inpi.gov.br/menu-

servicos/patente/classificacao-de-patentes Acesso em: 7 nov. 2019.

LAKATOS, Eva Maria; MARCONI, Marina de Andrade. Fundamentos de metodologia científica. 5. ed. São Paulo: Atlas, 2003

MOWERY, D.; SAMPAT, B. Universities in national innovation systems. In: FARGERBERG, J; MOWERY, D.; NELSON, R. (Eds.) The Oxford handbook of innovation. Oxford University, 2005.

NETO, I. R; NEHME. C. Gestão do conhecimento, sistemas de inovação e complexidade. Parcerias Estratégicas. Brasília-DF. V. 17. N 34. P 65-86.

Douglass C. North. Institutions. The Journal of Economic Perspectives, Vol. 5, No. 1. (Winter, 1991), pp. $97-112$.

OLIVEIRA JR. A. A universidade como polo de desenvolvimento local/regional. Caderno de Geografia, v.24, número especial 1. Universidade Federal de Uberlândia. Câmpus Pontal, 2014.

PINHO. Marcelo. Mais do que se supõe, menos do que se precisa: relações entre universidades e empresas no Brasil. P 26-35 In: Estudos de caso da interação universidade-empresa no Brasil. FACE, UFMG, 2018.

PRODANOV. Cleber C; FREITAS. Ernani C. Metodologia do trabalho científico [recurso eletrônico]: métodos e técnicas da pesquisa e do trabalho acadêmico. Universidade FEEVALE. $2^{\mathrm{a}}$ ed. Novo Hamburgo - Rio Grande do Sul - Brasil

PROEX. Núcleos de Extensão. 2012. Disponível em: https://ww2.uft.edu.br/index.php/proex/gruposcomissoes-e-nucleos/10867-nucleos-de-extensao Acesso em 20 nov.2019
RODRIGUES, Ediglei Dias. Análise da ambiência institucional de ciência, tecnologia e inovação (C,T\&I) na Amazônia Legal. Dissertação de Mestrado - Universidade Federal do Tocantins, Programa de Pós-Graduação em Desenvolvimento Regional, 2013. Palmas, 2013. 136f.

SCHUMPETER, J. Teoria do Desenvolvimento Econômico. Editora Nova Cultural Ltda. São Paulo. Edição Original em Dunker \& Humblot, 1964.

SILVA, Eliane G. A gestão da infra-estrutura física das Universidades no contexto do planejamento estratégico: estudo de caso em uma instituição universitária goiana. Florianópolis, UFSC, Programa de pós-graduação em Engenharia de Produção, 2003. p.113. Disponível em https://core.ac.uk/download/pdf/30366329.pdf Acesso em 18 nov.2019

TAYLOR, John. The response of governments and universities to globalization and internalization in higher education. In: MARINGE,Felix; FOSKETT, Nick (Org.). Globalization and internationalization in higher education: theoretical, strategic and management perspectives. London: Continuum International Publishing Group, 2010. p. 83-96.

TORKOMIAN, A. L. V. Gestão de tecnologia na pesquisa acadêmica: o caso de São Carlos. 1997. 303 f. Tese (Doutorado em Administração) - Universidade de São Paulo, São Paulo, 1997.

TORKOMIAN, Ana Lúcia Vitale. Panorama dos núcleos de inovação tecnológica no Brasil. In: SANTOS, Marli Elizabeth Ritter dos; TOLEDO, Patricia Tavares Magalhães de; LOTUFO, Roberto de Alencar (Org.). Campinas: Komedi, 2009. p. 21-39.

Universidade Federal do Tocantins - UFT. De olho na inovação tecnológica, UFT inaugura Incubadora de Empresas em Gurupi. 2013. Disponível em https://ww2.uft.edu.br/index.php/es/ultimasnoticias/12052-de-olho-na-inovacao-tecnologica-uftinaugura-incubadora-de-empresas-em-gurupi Acesso em 19.nov 2019

UFT. Instituto de Pesquisa e Extensão do Empreendedorismo Inovador do Tocantins (IpexEito). 2016b. Disponível em: https://ww2.uft.edu.br/index.php/institutos/ipex-eito Acesso em 20 nov. 2019 
VERGARA, Sylvia C. Projetos e Relatórios de Pesquisa em Administração. 494p. 2. Ed. São Paulo. Editora Atlas S.A. 1998.
YANG, F; ZHANG, X,. Study on complexity of Knowledge-typed workers. Science \& Technology Progress and Policy. 2010. 